\title{
APOE Genotype Influences Functional Status Among Elderly Without Dementia
}

\author{
Steven M. Albert, Barry Gurland, Gladys Maestre, Diane M. Jacobs, Yaakov Stern, \\ and Richard Mayeux \\ Gertrude H. Sergievsky Center (S.M.A., D.M.J., Y.S., R.M.), Department of Neurology (S.M.A., D.M.J., Y.S., R.M.), and \\ Pathology (G.M.), Center for Geriatrics and Gerontology (B.G.), Center for Alzheimer's Research in the City of New \\ York (B.G., G.M., Y.S., R.M.), and Division of Epidemiology (R.M.) at Columbia University, and Department of \\ Biological Psychiatry (Y.S., R.M.), New York State Psychiatric Institute, New York, New York
}

The presence of apolipoprotein- 44 (APOEE4) significantly increases the risk of Alzheimer's disease (AD). The association between $A P O E-\epsilon 4$ status and functional abilities was explored further in a multicultural sample of community-dwelling, nondemented elders. The sample was limited to cognitively-intact, community-dwelling elders, who were free of stroke or other neurologic disability. In 218 elders who met research criteria, the presence of $A P O-\epsilon 4$ was associated with poorer functional status, apart from the effects of neuropsychological performance, gender, age, and education (OR $=2.5,95 \%$ CI: $1.3,4.9)$. In 158 subjects without an $A P O E-\epsilon 4$ allele, $50 \%$ reported no functional limitation; in the 60 subjects with an $\epsilon 4$ allele, only $28 \%$ reported no functional limitation $(P<.01)$. The relationship was not explained by the distribution of co-morbidities. The association between poorer function and the presence of an $A P O E-\epsilon 4$ allele was evident in each ethnic group. In path analyses, the presence of an $A P O E-\epsilon 4$ allele was associated with decreased functional ability in non-demented elders not simply through an association with poorer cognitive status, but also independently. These results suggest that the APOE-e4 genotype is associated with functional deficit in people with normal neuropsychological profiles. @C 1995 Wiley-Liss, Inc.

KEY WORDS: apolipoprotein E, function, cognition, aging, Alzheimer's disease

Received for publication December 20, 1994; revision received May 16, 1995.

Address reprint requests to Dr. Richard Mayeux, Gertrude H. Sergievsky Center, Columbia University, 630 West 168th Street, New York, NY 10032.

\section{INTRODUCTION}

The prevalence of an $A P O E-\epsilon 4$ allele is increased among patients with Alzheimer's disease (AD), both sporadic and familial, compared to controls. ${ }^{1-9}$ The location of $A P O E$ on chromosome $19 \mathrm{q} 13.2$, an area already linked to late-onset familial $\mathrm{AD},{ }^{10}$ strengthens the plausibility of this relationship. In addition, $A P O E$ $\epsilon 4$ alleles were found to be less frequent than other polymorphisms in centenarians, suggesting a relationship to longevity, ${ }^{11}$ as confirmed by studies relating $A P O E-\epsilon 4$ to congestive heart disease ${ }^{12}$ and ischemic cerebrovascular disease. ${ }^{13}$

We explored potential associations between $A P O E$ status and function in non-demented elders. Because these elders are living in the community and are, for the most part, healthy, we suspected that $A P O E$ status might affect high-level functional status, as assessed by self-ratings of competence in performing tasks associated with independent living.

\section{METHODS AND MATERIALS Subjects}

Subjects in this study were non-demented elders free of dementia from a community study in northern Manhattan, New York; all received clinical assessments that included neuropsychological testing. The subjects are representative of community-dwelling, non-demented elders who use health services and were recruited without regard to genotype or functional status.

The 218 subjects assessed in this study were recruited from three sources: a population-based community survey of a random sample of elders $(\mathbf{n}=97)$, a community registry of people who sought medical or social services $(n=93)$, and people who had been assessed at the Columbia-Presbyterian Memory Disorders Clinic $(\mathbf{n}=28)$. The three groups did not significantly differ in sociodemographic features or neuropsychological performance. Nor did the distribution of $A P O E$ genotypes differ between the groups. The age range of subjects was 58-93 years.

\section{Definition and Assessment of Healthy Elders}

None of the subjects met DSM-III (3rd Edition, Revised) criteria for dementia, and those with stroke, de-

(C) 1995 Wiley-Liss, Inc. 
pression, or Parkinson's disease were excluded. A standardized neuropsychological battery was used to assess cognitive performance. Using a set of previously described cut scores, ${ }^{14}$ neuropsychological performance on the battery was summarized according to whether subjects had no or only one low test score ("no cognitive deficit, no apparent clinical significance"), or low scores on two or more tests ("low test scores with possible clinical significance"). Subjects with low scores on more than two tests who also had functional deficits extensive enough to warrant the label of "questionable dementia" (equivalent to a Clinical Dementia Rating ${ }^{15}$ score of 0.5 ) were excluded. Because of its sensitivity to early stages of dementing disease, additional analyses were conducted with the Selective Reminding Test (SRT, total and delayed recall), ${ }^{16,17}$ one of the 15 tests in the battery.

\section{Functional Outcomes}

Functional status was assessed with the Schwab and England Activities of Daily Living scale, ${ }^{18}$ the Blessed Dementia Rating Scale (BDRS, Part I), ${ }^{19}$ and the Barthel index. ${ }^{20}$ The Schwab and England ADL scale is a measure of self-reported overall independence in functional activities. This modified visual analogue scale ranges from 0 (bedridden) to $100 \%$ (completely independent) in increments of $10 \%$; each decile is anchored to behavioral descriptions indicating degree of difficulty with activities and need for help. The BDRS assesses performance in the activities of daily living (ADL) as well as self-perceived cognitive status. The Barthel function items assess need for help in ADLs. Both scales were summed to form composites of 11 and 7 items, respectively.

Medical histories and sociodemographic information were also obtained. Racial-ethnic assignment of subjects followed the format used in the 1990 Census. ${ }^{21}$

\section{DNA Allelotyping}

The procedure for DNA allelotyping at the APOE locus has been previously described. ${ }^{\circ}$ Data regarding $A P O E$ genotypes were shielded from investigators.

\section{Data Analyses}

Allelic frequencies for subjects were determined. The sample was divided according to those with no $A P O E$ $\epsilon 4$ allele $(n=158)$ and those with one or two alleles ( $n$ $=60$ ). The small number of subjects homozygous for $A P O E-\epsilon 4(n=4)$ precluded analysis of these subjects as separate group. Univariate analyses explored whether the two genotype groups differed in sociodemographic features, distribution of comorbidities, neuropsychological status, and functional outcomes. To control for potential confounders, multivariate logistic models were used. In these models, the primary outcome was functional ability on the Schwab \& England measure, which was dichotomized to compare those reporting no functional impairment (score of 100) with those reporting any deficit (score $<100$ ). Alternative cutpoints for this measure were also assessed.

In addition, a causal model using path analysis ${ }^{22}$ was developed to assess relationships between $A P O E-\epsilon 4$ status, neuropsychological performance, and functional ability. The path model enables one to assess the extent to which $A P O E$ status may affect functional status directly and also indirectly through its association with neuropsychological performance.

\section{RESULTS \\ Characteristics of Study Sample}

Allelic frequencies for the sample, stratified by ethnicity, are shown in Table I. Consistent with previous observations, ${ }^{9}$ African-Americans had the highest frequency of $A P O E-\epsilon 4$ alleles (22\%), compared to $9 \%$ among Caucasians and $12 \%$ among Hispanics.

Sociodemographic and other characteristics of the sample, by APOE status, are shown in Table II. Gender, age, and education did not differ according to $A P O E-\epsilon 4$ status. Also, $A P O E-\epsilon 4$ status was not related to neuropsychological status; the proportion of people with low scores on the neuropsychological battery was roughly the same in the $A P O E-\epsilon 4$ groups, and memory performance as assessed by mean SRT scores did not differ.

Examination of medical histories showed that the groups did not significantly differ in the prevalence of 12 medical conditions. Also, they did not differ in total number of medical conditions, medications, or surgical procedures reported.

\section{APOE- 64 and Functional Ability}

Table II shows that subjects with one or more $A P O E$ $\epsilon 4$ alleles reported significantly poorer scores on measures assessing high-level function. Mean scores on the Schwab \& England ADL self-rating were significantly lower among subjects with $A P O E$ - $\epsilon 4$ ( 87.3 vs. $80.9, P<$ $.05)$. Half $(50 \%)$ of the non- $A P O E$ - $\epsilon 4$ group reported complete independence in ADL tasks, compared to only $28 \%$ among those with an APOE- $\epsilon 4$ allele $(P<.01)$.

In a multivariate logistic regression model, in which age, gender, education, and neuropsychological measures were entered, $A P O E$ - $\epsilon 4$ status remained a significant predictor of functional deficit $(\mathrm{OR}=2.5,95 \% \mathrm{CI}$ : $1.3,4.9$ ). In this model, age was the only other significant predictor. The groups significantly differed in Schwab \& England scores when the scale was dichotomized at lower levels of functional ability $(70,80$, and $90 \%$ of optimal function). The complete distribution of Schwab \& England scores for each group is shown in Figure 1.

Subjects with the $A P O E$ - $\epsilon 4$ genotype reported more impairment on the Blessed Dementia Rating Scale summary score as well. The poorer score is largely due to greater reported difficulty with tasks involving memory. For example, $44 \%$ of people with the APOE- $\epsilon 4$

TABLE I. Apo-E Allelic Frequencies, by Ethnicity*

\begin{tabular}{llll}
\hline & $\mathrm{e} 2$ & $\mathrm{e} 3$ & $\mathrm{e} 4$ \\
\hline Caucasian $(\mathrm{n}=43)$ & .06 & .85 & .09 \\
African-American $(\mathrm{n}=62)$ & .07 & .71 & .22 \\
Hispanic $(\mathrm{n}=96)$ & .04 & .84 & .12 \\
\hline
\end{tabular}

$* n=201$ (ethnicity unknown in 12 subjects). 
TABLE II. Comparison of Non-Demented Elders, by Apo-e4 Status

\begin{tabular}{|c|c|c|}
\hline & $\begin{array}{l}\text { No e4 Allele } \\
\quad(\mathrm{n}=158)\end{array}$ & $\begin{array}{l}\geq 1 \text { e4 Allele } \\
\quad(\mathrm{n}=60)\end{array}$ \\
\hline \multicolumn{3}{|l|}{ Sociodemographics } \\
\hline Gender ( $\%$ female $)$ & 72 & 80 \\
\hline Age (years) & 74.1 & 75.3 \\
\hline Education (highest grade of school) & 8.4 & 8.2 \\
\hline \multicolumn{3}{|l|}{ Neuropsychological status } \\
\hline SRT total recall & 39.2 & 38.2 \\
\hline SRT delayed recall & 5.6 & 5.3 \\
\hline $\begin{array}{l}\text { Low score } \geq 2 \text { tests, } \\
\text { neuropsychological battery (\%) }\end{array}$ & 41.7 & 48.3 \\
\hline \multicolumn{3}{|l|}{ Functional Status } \\
\hline Schwab \& England* & 87.3 & 80.9 \\
\hline No ADL impairment $(\%)^{* *}$ & 50 & 28 \\
\hline $\begin{array}{l}\text { Blessed Dementia Rating Scale } \\
\text { (BDRS), Part I*** } \\
\text { Barthel Index }\end{array}$ & $\begin{array}{r}9.95 \\
69\end{array}$ & $\begin{array}{r}18.57 \\
88\end{array}$ \\
\hline
\end{tabular}

$* P<.05 ; * * P<.01$. No ADL impairment indicated by score of 100 on Schwab \& England scale. SRT, Selective Reminding Test.

genotype reported at least some difficulty with memory for lists, compared to only $25 \%$ among those without the $A P O E-\epsilon 4$ genotype. However, the association between $A P O E-\epsilon 4$ and functional independence remained significant even when entering this memory item into the logistic model $(\mathrm{OR}=2.2 ; 95 \% \mathrm{CI}: 1.1,4.5)$. Measures of more severe functional disability, as assessed by the Barthel scale, did not differ by $A P O E-\epsilon 4$ status.

Table III presents allele frequencies for subjects with and without any ADL deficit (as assessed by a score of 100 on the Schwab \& England measure), stratified by ethnicity. In each ethnic group, subjects reporting poorer function had a higher frequency of $A P O E-\epsilon 4$ alleles. Also, subjects with the $A P O E-\epsilon 2$ genotype $(\epsilon 2 / \epsilon 2, \epsilon 2 / \epsilon 3)$ were more likely to be completely independent in $\mathrm{ADL}$ function (OR $=2.6 ; 95 \% \mathrm{CI}: 1.3,5.0$ ).

Logistic regression analyses showed that the presence of one or more $A P O E-\epsilon 4$ alleles is associated with poorer function in each ethnic group (odds ratio for Caucasians 1.9, African-Americans 1.6, and Hispanics 6.9); however, owing to small sample sizes, these results achieved statistical significance only in the Hispanic sample.

Finally, a path analysis was conducted to test whether $A P O E$ - $\epsilon 4$ status was associated with poorer function directly, or only through its association with

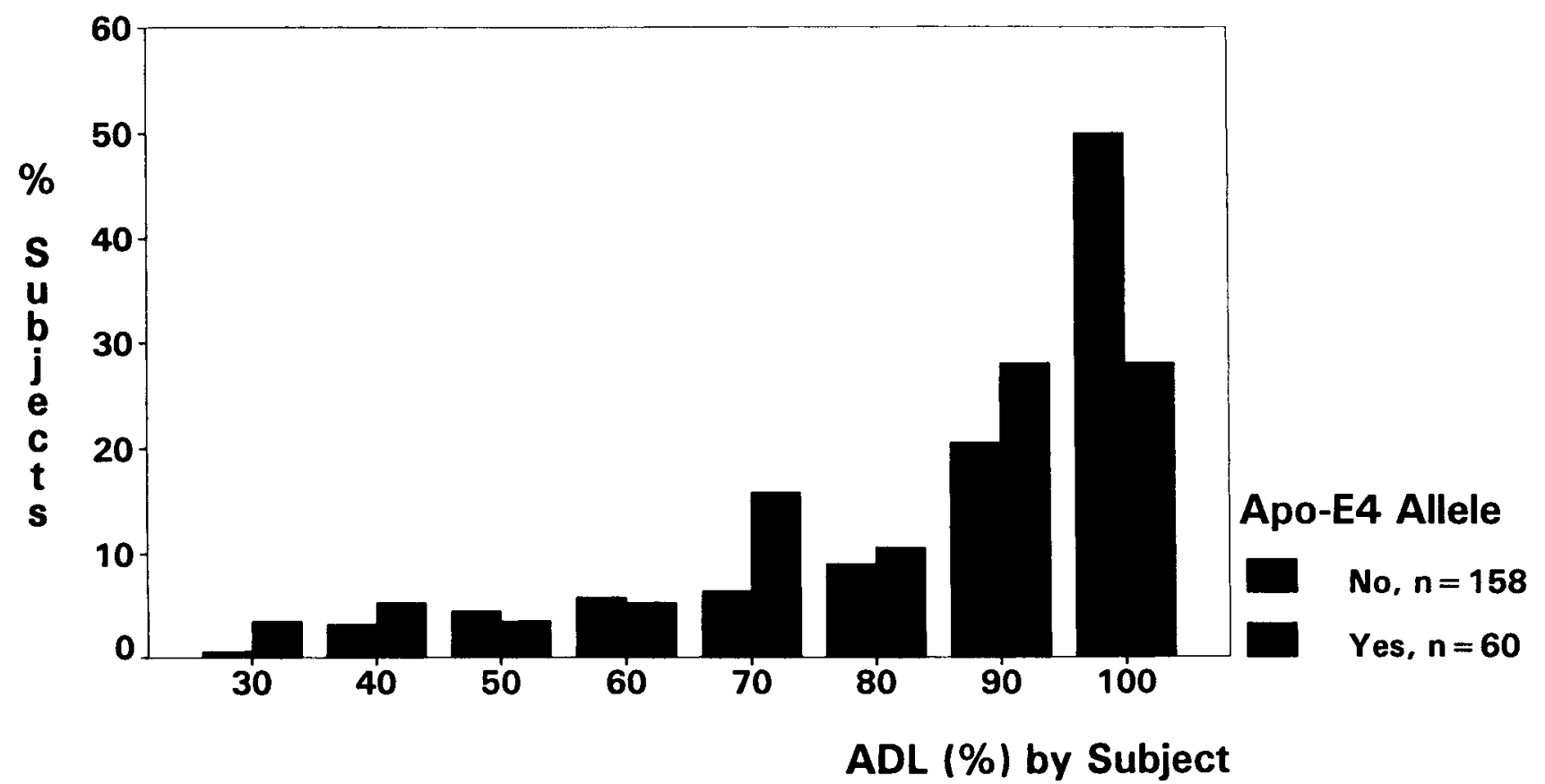

Fig. 1. ADL (\%) by Apo-E4 status, non-demented subjects. 
TABLE III. Distribution of Apo-E Genotypes Among Non-Demented Elders, by Ethnicity and Functional Status*

\begin{tabular}{|c|c|c|c|c|c|c|c|c|c|}
\hline & \multicolumn{6}{|c|}{ Apo-E genotypes } & \multicolumn{3}{|c|}{ Allele frequency } \\
\hline & $3 / 3$ & $2 / 3$ & $3 / 4$ & $4 / 4$ & $4 / 2$ & $2 / 2$ & Apo-e3 & Apo-e4 & Apo-e2 \\
\hline \multicolumn{10}{|l|}{ Caucasian } \\
\hline$<100 \%$ ADL $(\mathrm{n}=19)$ & 14 & 1 & 2 & 1 & 1 & 0 & .82 & .13 & .05 \\
\hline $100 \%$ ADL $(\mathrm{n}=24)$ & 18 & 3 & 3 & 0 & 0 & 0 & .88 & .06 & .06 \\
\hline \multicolumn{10}{|l|}{ African-American } \\
\hline$<100 \%$ ADL $(\mathrm{n}=39)$ & 18 & 3 & 16 & 1 & 1 & 0 & .72 & .24 & .04 \\
\hline $100 \%$ ADL $(\mathrm{n}=23)$ & 11 & 3 & 8 & 0 & 0 & 1 & .72 & .17 & .11 \\
\hline \multicolumn{10}{|l|}{ Hispanic } \\
\hline$<100 \%$ ADL $(\mathrm{n}=53)$ & 34 & 1 & 15 & 2 & 1 & 0 & .79 & .19 & .02 \\
\hline $100 \%$ ADL $(\mathrm{n}=43)$ & 36 & 3 & 3 & 0 & 0 & 1 & .91 & .03 & .06 \\
\hline
\end{tabular}

* 100\% ADL indicates score of 100 on Schwab \& England scale ("completely independent; able to do all chores without slowness, difficulty, or impairment"). $n=201$ (ethnicity unknown in 12 subjects).

poorer cognitive performance. The model shows that $A P O E$ - $\epsilon 4$ is associated with poorer functional status in two ways: 1) through a weak association with lower performance on neuropsychological measures $(r=.06$, NS), which in turn are associated with poorer functional status $(r=.20, P=.003)$; and 2 ) through an independent effect on functional status $(\mathrm{r}=.16, P=.02)$. That is, within each level of neuropsychological performance (as assessed by battery performance or SRT score), subjects with one or more APOE- $\epsilon 4$ alleles still reported poorer functional status.

\section{DISCUSSION}

Our data suggest that the $A P O E$ - $\epsilon 4$ genotype is associated with poorer functional status among nondemented, community-dwelling elders. This relationship was observed in all three ethnic groups, though small sample sizes require that this finding be replicated in other studies. The relationship between genotype and functional status does not appear to be an artifact of other differences between the genotypes that may be correlated with functional status, such as the distribution of age, gender, or education; neuropsychological performance; or co-morbid conditions and service utilization.

The genotype groups did not differ in measures of more severe functional deficit (e.g., the Barthel measure), but rather in reports of general functional ability. Here differences are large: $50 \%$ of the non-APOE- $\epsilon 4$ group reported complete independence in ADLs compared to only $28 \%$ among those with $A P O E$ - $\epsilon 4$ allele. The association between $A P O E$ - $\epsilon 4$ and more subtle deficits is reasonable because subjects in this study were explicitly ascertained as healthy elders; all were residing in the community, and all were free of clinically significant cognitive deficit. Thus, it might be expected that elders in the sample would not show the severe functional deficits assessed in the Barthel measures of disability.

Having established a relationship between $A P O E$ and functional ability in this sample, two questions need to be addressed. First, is the association between $A P O E-\epsilon 4$ and poorer function artifactual, or does the association demonstrate a true independent genetic effect? Second, what biologic mechanism, if any, could account for this effect?
With regard to the first question, the increased risk of functional deficit may indicate a genetic effect. Confounding factors were controlled in these analyses (e.g., sociodemographic variation, comorbid conditions, and neuropsychological status), reducing the likelihood that the observed association is spurious. Also, the association was found among each of the ethnic groups, an important finding given differences in allelic frequencies across the groups. The significant association between $A P O E-\epsilon 4$ status and functional outcomes in models that control for differences in neuropsychological profile suggests an independent effect of this genotype on functional status. While the genotype groups did not differ in neuropsychological profiles (as assessed by a general neuropsychological battery, including a test notable for sensitivity to early effects of dementia), people with $A P O E-\epsilon 4$ did report poorer function in BDRS tasks involving memory (e.g., ability to remember lists). However, $A P O E-\epsilon 4$ status was a significant, independent predictor of functional status in logistic regression models that included BDRS memory items. This, combined with the path model results, is evidence that $A P O E$ - $\epsilon 4$ and cognitive status each independently increase the risk that functional ability may be impaired in nondemented elders.

Turning to the question of a mechanism for this genetic effect, it should be noted that subjects with an $A P O E$ - $\epsilon 4$ allele in this sample may or may not go on to develop Alzheimer's disease; conversely, some of the subjects without an $A P O E-\epsilon 4$ allele may also develop dementia. The association between $A P O E$ genotype and functional ability reported here may involve mechanisms distinct from those postulated to explain the increased risk of Alzheimer's disease associated with this genotype. The question remains open. Our findings should be seen in the light of other research that shows an effect of $A P O E-\epsilon 4$ on measures of cognitive status and brain function in nondemented elders. For example, Feskins et al. ${ }^{23}$ and Reed et al. ${ }^{24}$ reported significant associations between $A P O E$ allelic status and cognitive performance, while Small et $\mathrm{al}^{25}$ found a significant association between $A P O E$ - $\epsilon 4$ and measures of cerebral metabolic rate. Longitudinal follow-up to detect onset of dementia is required, in our research as well as in these studies, to determine if these associa- 
tions represent early manifestations of pathophysiological processes typical of Alzheimer's disease or some other process more directly linked to $A P O E-\epsilon 4$ protein levels, as suggested by Poirier. ${ }^{26}$

Finally, compared to other Caucasian populations (in which $A P O E-\epsilon 4$ frequencies range from $12-15 \%$ ), the $A P O E-64$ allelic frequency in this sample is low. The low frequency may reflect the high incidence of Alzheimer's disease at this age among Caucasians with $\epsilon 4 / \epsilon 4$ and $\epsilon 3 / \epsilon 4$ genotypes. ${ }^{27}$ However, in the cross-sectional design adopted here, this selection effect does not bias associations between genotype and functional outcome. Also, the high frequency of $A P O E-\epsilon 4$ alleles in the African-American sample is notable; Hendrie et al. $^{28}$ and Saunders et al. ${ }^{9}$ report gene frequencies in African-Americans more similar to those of Caucasians. The cross-sectional analysis reported here establishes this association only for similar populations of non-demented, community-dwelling elders. Inferences about association in this study would be threatened if the temporal relationship between exposure and outcome were not clear, but this is not the case for genetic exposures. ${ }^{29}$ Finally, bias is unlikely because we have used a cohort unselected for genotype or functional ability and assessed all subjects with equivalent measures.

\section{ACKNOWLEDGMENTS}

Research was supported by federal grants AG07232, AG10963, and RR00645, the Alzheimer's Association (FSA-93-026), and the Charles S. Robertson Memorial Gift for Alzheimer's Research from the Banbury Fund.

\section{REFERENCES}

1. Strittmatter WJ, et al. (1993): Apolipoprotein E: High affinity binding to beta-amyloid and increased frequency of type 4 allele in late-onset familial Alzheimer's disease. Proc Natl Acad Sci USA 90:1977-1981.

2. Saunders AM, et al. (1993): Association of apolipoprotein E allele e4 with late-onset familial and sporadic Alzheimer's disease. Neurology 43:1467-1472.

3. Corder EH, et al. (1993): Gene dose of apolipoprotein-E type 4 allele and the risk of Alzheimer's disease in late-onset families. Science 261:921-923.

4. Poirer J, et al. (1993): Apolipoprotein E polymorphism and Alzheimer's disease. Lancet 342:697-699.

5. Payami H, et al. (1993): Apolipoprotein-E genotype and Alzheimer's disease. Lancet 342:738.

6. Brogaonkar DS, et al. (1993): Linkage of late-onset Alzheimer's disease with apolipoprotein-E type 4 on chromosome 19. Lancet 342:625.

7. Saunders AM, et al. (1993): Apolipoprotein-E e4 allele distributions in late-onset Alzheimer's disease and in other amyloid-forming diseases. Lancet 342:710-711.
8. Mayeux R, et al. (1993): The apolipoprotein e4 allele in patients with Alzheimer's disease. Ann Neurol 34:752-754.

9. Maestre G, et al. (1995): Apolipoprotein-E and Alzheimer's disease: Ethnic variation in genotype risks. Ann Neurol 37:254-259.

10. Pericak-Vance MA, et al. (1991): Linkage studies in familial Alzheimer's disease: Evidence for chromosome 19 linkage. Am J Hum Genet 48:1034-1050.

11. Schachter F, et al. (1994): Genetic associations with human longevity at the APOE and ACE loci. Nature Genet 6:29-32.

12. Davignon J, Gregg RE, Sing CF (1988): Apolipoprotein E polymorphism and atherosclerosis. Arteriosclerosis 8:1-21.

13. Couderc R, Mahieux F, Bailleul S, et al. (1993): Prevalence of apolipoprotein e phenotypes in ischemic cerebrovascular disease. Stroke 24:661-664.

14. Stern Y, et al. (1992): Diagnosis of dementia in a heterogeneous population: Development of a neuropsychological paradigm and quantified correction for education. Arch Neurol 49:453-460.

15. Hughes CP, et al. (1982): A new clinical scale for the staging of dementia. Br J Psychiatry 140:566-572.

16. Jacobs DM, Sano M, Dooneief G, Marder K, Bell KL, Stern Y (1995): Neuropsychological detection and characterization of preclinical Alzheimer's disease. Neurology 45:957-962.

17. Mazur DM, Slivinski M, Lipton DB, et al. (1994): Neuropsychological prediction of dementia and absence of dementia in healthy elderly persons. Neurology 44:1427-1432.

18. Schwab JF, et al. (1969): Projection technique for evaluating surgery in Parkinson's disease. In FS Gillinghan, MN Donaldson (eds): "Third Symposium on Parkinson's Disease." Edinburgh: E\&S Livingstone, pp 152-157.

19. Blessed G, et al. (1968): The association between quantitative measures of dementia and of senile changes in the cerebral grey matter of elderly subjects. Br J Psychiatry 225:797-811.

20. Mahoney FI, et al. (1965): Functional evaluation: The Barthel index. Maryland Med J 14:61-65.

21. "Census of Population and Housing, 1990: Summary Tape File 1" (1991): Technical documentation prepared by Bureau of Census. Washington, D.C.: Bureau of Census.

22. Pedhazur EA (1982): "Multiple Regression in Behavioral Research." New York: CBS College Publishing.

23. Feskins EJM, Havekes LM, Kalmijn S, et al. (1994): Apolipoprotein e4 allele and cognitive decline in elderly men. $\mathrm{Br}$ Med $\mathrm{J}$ 309:1202-1206.

24. Reed T, Carmelli D, Swan GE, et al. (1994): Lower cognitive performance in normal older adult male twins carrying the Apolipoprotein E $\in 4$ allele. Arch Neurol 51:1189-1192.

25. Small GW, Mazziotta JC, Collins MT, et al. (1995): Apolipoprotein E type 4 allele and cerebral glucose metabolism in relatives at risk for familial Alzheimer disease. JAMA 273:942-947.

26. Poirier $J$ (1994): Apolipoprotein $\mathrm{E}$ in animal models of CNS injury and in Alzheimer's disease. Trends Neurosci 17:525-530.

27. Roses AD, Strittmatter WJ, Pericak-Vance MA, et al. (1994): Clinical application of apolipoprotein E genotyping to Alzheimer's disease. Lancet 343:1564-1565.

28. Hendrie HC, Hall KS, Hui S, et al. 91995): Apolipoprotein E genotypes and Alzheimer's disease in a community study of elderly African-Americans. Ann Neurol 37:118-120.

29. Rothman KJ (1986): "Modern Epidemiology." Boston: Little, Brown. 